\title{
The Habitat Demonstration Unit Project Overview
}

\author{
K. J. Kennedy ${ }^{1}$, T.R.Gill ${ }^{2}$, T. O. Tri $^{3}$, and A. S. Howe ${ }^{4}$ \\ 1 Architect, NASA Johnson Space Center. Mail Code EA3, 2101 NASA Parkway, Houston, TX 77058; \\ PH (281) 483 6629; email: Kriss.J.Kennedy@nasa.gov \\ 2 Engineer, NASA Kennedy Space Center. Mail Code LX-M, Kennedy Space Center, FL 32899; PH \\ (321) 867 5824; email: Tracy.R.Gill@nasa.gov \\ 3 Engineer, NASA Johnson Space Center. Mail Code EA3, 2101 NASA Parkway, Houston, TX 77058; \\ PH (281) 483 9234; email: Terry.O.Tri@nasa.gov \\ 4 Architect, NASA Jet Propulsion Laboratory. Mail Code EA3, 4800 Oak Grove Drive, Pasadena, CA \\ 91109; PH (818) 354 4492; email: Alan.S.Howe@nasa.gov
}

\section{Abstract}

This paper will describe an overview of the National Aeronautics and Space Administration (NASA) led multi-center Habitat Demonstration Unit (HDU) Project. The HDU project is a "technology-pull" project that integrates technologies and innovations from numerous NASA centers. This project will be used to investigate and validate surface architectures, operations concepts, and requirements definition of various habitation concepts. The first habitation configuration this project will build and test is the Pressurized Excursion Module (PEM). This habitat configuration - the PEM - is based on the Constellation Architecture Scenario 12.1 concept of a vertically oriented habitat module. The HDU project will be tested as part of the 2010 Desert Research and Technologies Simulations (D-RATS) test objectives. The purpose of this project is to develop, integrate, test, and evaluate a habitat configuration in the context of the mission architectures and surface operation concepts. A multi-center approach will be leveraged to build, integrate, and test the PEM through a shared collaborative effort of multiple NASA centers. The HDU project is part of the strategic plan from the Exploration Systems Mission Directorate (ESMD) Directorate Integration Office (DIO) and the Lunar Surface Systems Project Office (LSSPO) to test surface elements in a surface analog environment. The 2010 analog field test will include two Lunar Electric Rovers (LER) and the PEM among other surface demonstration elements. This paper will describe the overall objectives, its various habitat configurations, strategic plan, and technology integration as it pertains to the 2010 and 2011 field analog tests.

To accomplish the development of the PEM from conception in June 2009 to rollout for operations in July 2010, the HDU project team is using a set of design standards to define the interfaces between the various systems of PEM and to the payloads, such as the Geology Lab, that those systems will support. Scheduled activities such as early fit-checks and the utilization of a habitat avionics test bed prior to equipment installation into PEM are planned to facilitate the integration process. 


\section{Background}

A technique being utilized in NASA's lunar architecture analysis is analog testing of the lunar environment in desert locales. Running through potential "day in the life" scenarios at a lunar outpost with prototype equipment allows designers insight into the utilization of the proposed systems and refines architecture and operations concepts. A series of Desert Research and Technology Studies (DesertRaTS or DRaTS) have been held in locations such as Moses Lake, Washington and Black Point Lava Flow, Arizona, where the most recent test in September 2009 was performed with a Lunar Electric Rover, and a fourteen day excursion was practiced. The 2010 session of Desert-RaTS is planned for Black Point Lava Flow where two LERs will operate together and add a full scale lunar habitat prototype, the Habitat Demonstration Unit to the two LERs to allow for a 14-28 day mission. A graphic example of the proposed lunar architecture 12.1 under evaluation at the Desert-RaTS 2010 campaign is pictured below in Figure 1. The Pressurized Excursion Module (PEM) to be represented by the HDU in 2010 is depicted in the center. Figure 2 illustrates the PEM floor plan configuration that will be evaluated during DRaTS. One difference in the version of the PEM depicted in that figure from the HDU version of the PEM is that the HDU version will allow for a second story loft rather than accommodate commodity storage tanks on its roof.

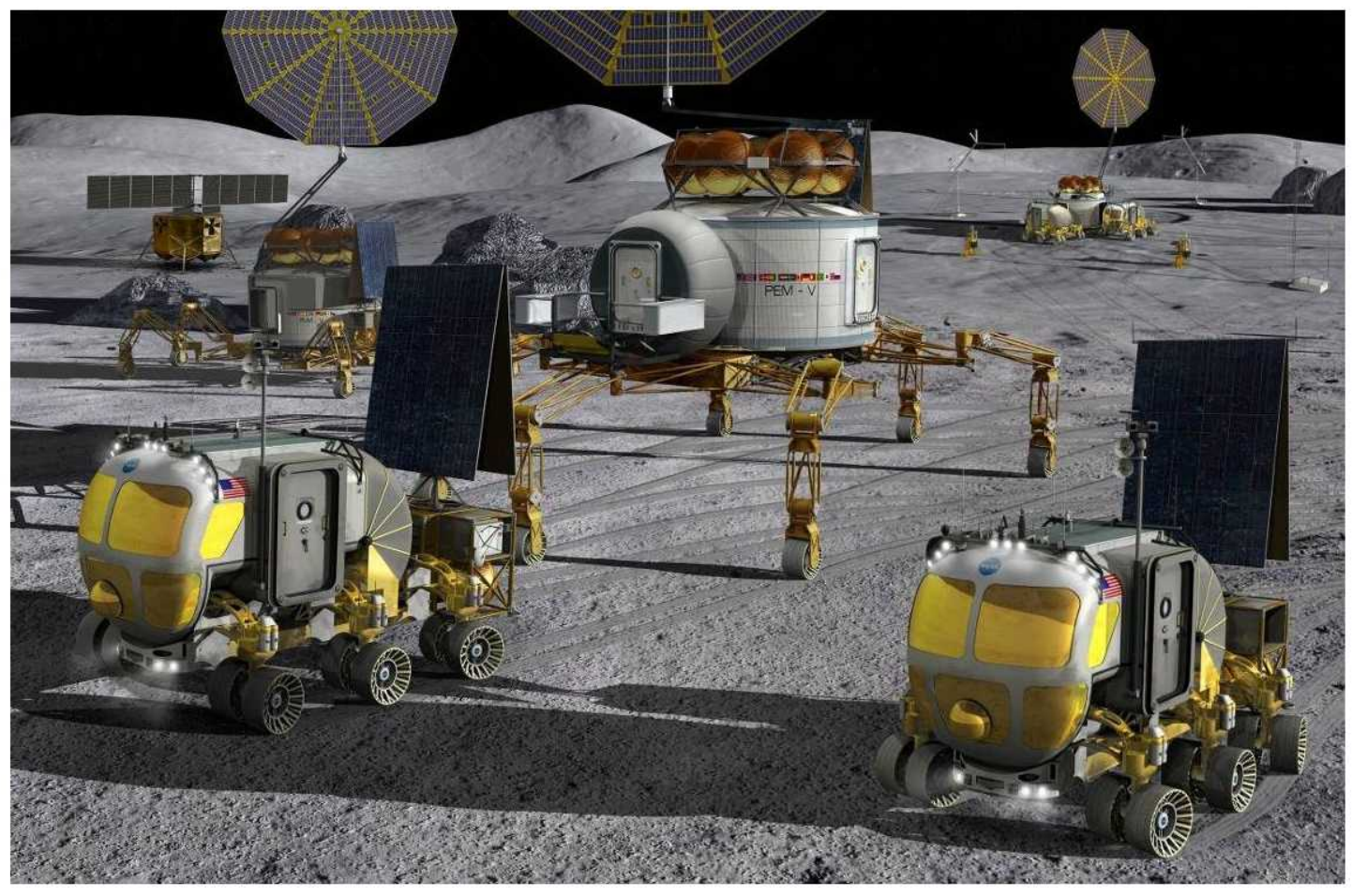

Figure 1, Illustration of Lunar Scenario 12.1 Excursion Configuration. 


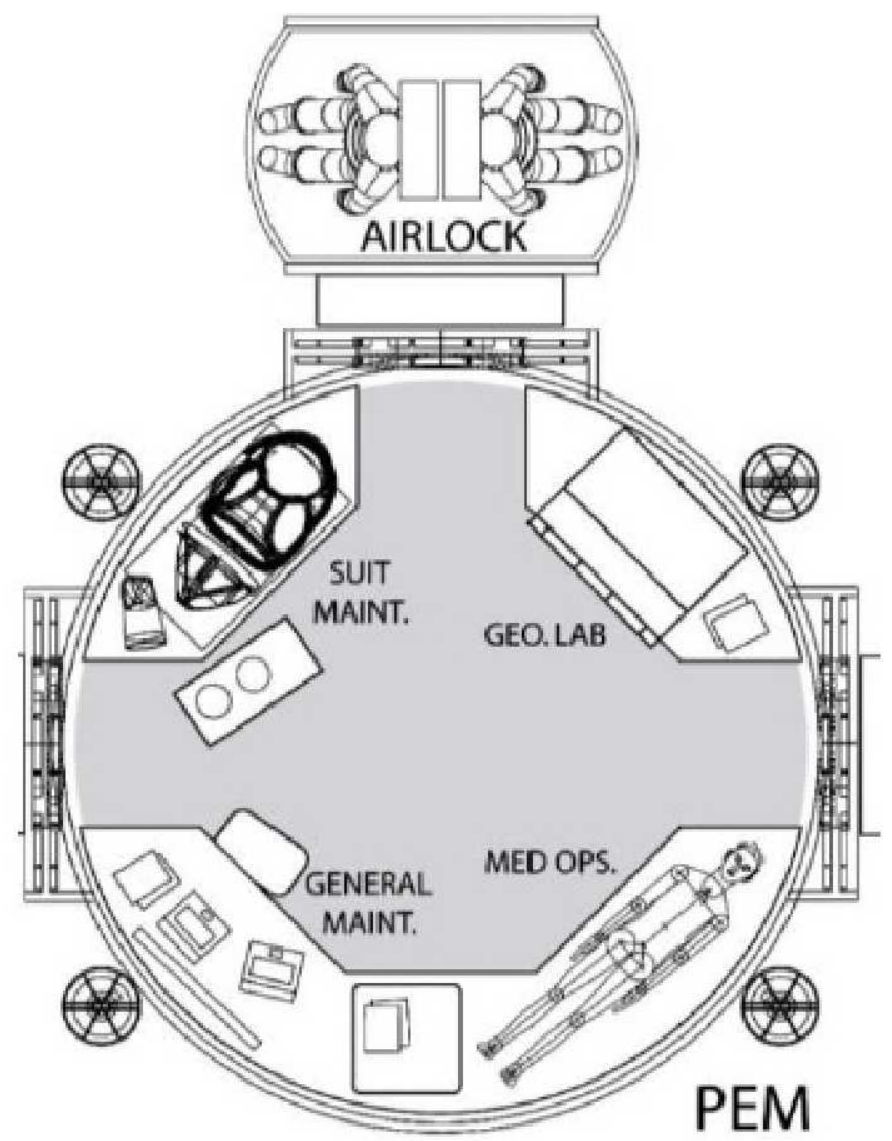

Figure 2, Lunar Scenario 12.1 Pressurized Excursion Module Configuration

The Constellation Architecture Team Lunar Scenario 12.0 surface habitation approach, concept, and assessments performed during the study definition focused on two primary habitation approaches: a horizontally-oriented habitation module (LS12.0) and a vertically-oriented habitation module (LS-12.1). The LSS Habitation Team defined a 12.1 lunar surface campaign, the associated outpost architecture (fig 3 ), habitation functionality, concept description, system integration strategy, mass and power resource estimates. The Scenario 12 architecture resulted from combining three previous scenarios after the Lunar Surface Systems (LSS) Project Office meeting in April 28-30, 2009. The best attributes from Scenario 4 "Optimized Exploration", Scenario 5 "Fission Surface Power System" and Scenario 8 "Initial Extensive Mobility" were combined into Scenario 12 along with an added emphasis on defining the excursion ConOps while the crew is away from the outpost location. These habitat configurations are the basis of the demonstration units that the HDU Project will integrate, build, assemble and test. 


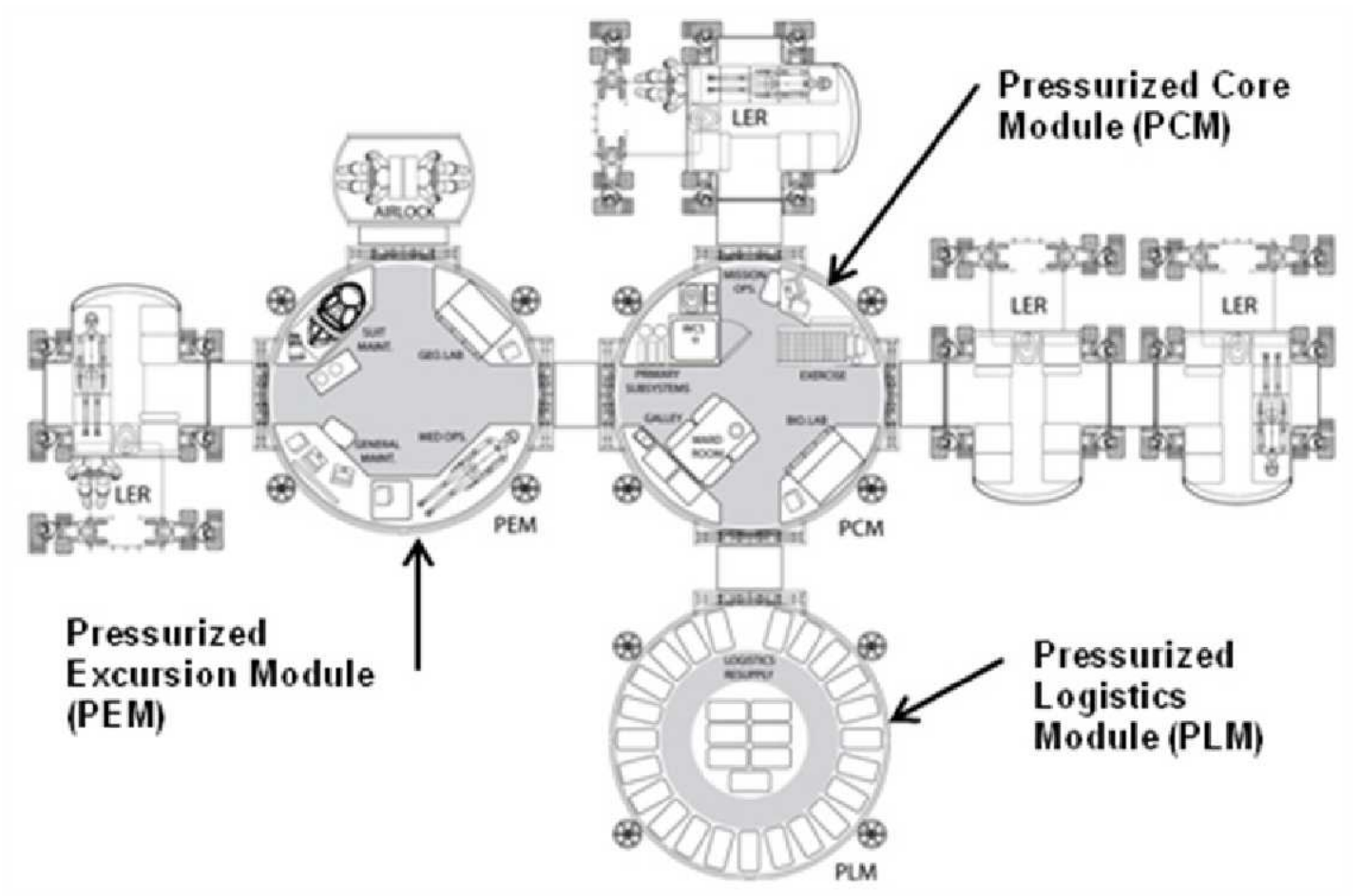

Figure 3, Plan View of Lunar Scenario 12.1 Outpost Configuration

\section{Strategic Development}

The HDU Project is a focused effort to build and test various technologies and Advanced Habitation Systems (AHS) early in the conceptual definition cycle exploiting low-cost rapid prototyping development techniques while drawing upon the agencies best and brightest engineers and architects. This early life-cycle tigerteam approach will help NASA to understand the various exploration architectures, define various concept-of-operations, derive habitation requirements, and refine technology needs while engaging our young engineers and academia. The HDU Project is a synthesis of configurational assessments and technology demonstrations (when and where applicable). It blends the Advanced Habitation Systems (AHS) strategic goals with the agency's rapid prototyping strategy of low-cost early mitigation of future habitation systems. The HDU Project enables early integration of exploration habitation developmental hardware and software systems independent of the exploration destination.

\section{Advanced Habitation Systems Technology}

The Advanced Habitation Systems (AHS) technology development project (in pre-formulation stage) strategic goals align with the agency's rapid prototyping strategy of low-cost, early mitigation of future habitation systems. The AHS project will develop habitation technologies that the HDU Project will corporate into various 
testing configurations. These two projects are closely coupled in development, integration, and testing. The "Vision" for AHS is to provide a light-weight, safe and reliable "intelligent" habitation system that has the capability for fully-integrated intelligent systems for autonomous operation, failure detection, analysis, and selfrepair facilities to support humans living and working in space and on other planetary bodies. This is analogous to a terrestrial home lasting 25 years with a low-carbon foot-print and Net-Zero resource consumption with no maintenance and operations required to live in it while seamlessly providing comfortable and safe living capabilities.

The AHS development strategy is to (1) make advanced habitation development affordable by coordinating NASA centers and enterprises to synergize technology needs; (2) develop advanced habitation through earth-based testing; (3) utilize flight demonstrations to increase confidence in Advanced Habitation Systems; and (4) incorporate a "sustainability" approach in the design, manufacturing, and testing. These strategic goals can further be decomposed into lower lever objectives.

1. Coordinate NASA Centers and Enterprises to Synergize Technology Needs

- High leverage technologies applicable to other disciplines (i.e., life support, materials, structures, robotics, computer systems, etc.)

- Technologies that reduce the risk or cost of other systems influenced by Advanced Habitat Systems, (i.e., space transportation, surface mobility, light weight structures)

- Develop technologies which are applicable to Space, Lunar and Mars habitats.

- Engage/Partner with industry and academia; Use University Grants, Small Business Innovative Research (SBIR's), Cooperative Agreements, and Internal Research \& Development to the maximum extent possible

- Develop technologies with viable Earth \& space commercial applications

2. Develop Advanced Habitation Through Earth-Based Testing

- Characterize and compare competing technologies for mission modeling and technology development planning

- Demonstrate environmental and mission suitability of Advanced Habitation concepts and systems

- Raise TRL and reduce risk/concerns of incorporation of advanced technologies into missions

- Utilize existing test facilities.

3. Utilize Flight Demonstrations to increase confidence in Advanced Habitation Systems

- Fly progressively more complex demonstration missions to minimize the risk and increase the confidence in use of Advanced Habitation Systems for NearEarth 100 day class human missions and Solar System 300-1000 day class human missions.

- Use ISS and Lunar opportunities for demonstrations and flight experience. 
4. Incorporate a "Sustainability" Approach in the Design, Manufacturing, and Testing

- Incorporate "Green Engineering" approaches, processes, and practices into Advanced Habitation Systems

- Select materials that are "green" oriented. (e.g. they have been either recycled or repurposed as opposed to using virgin stock materials such as large wood timber or raw steel)

- Select materials that will be recycled as part of the test article disposal process.

- Select materials and testing processes that will not be harmful to the environment.

\section{Habitat Demonstration Unit Project}

A multi-pronged approach with be utilized to support the HDU project through a shared, collaborative effort of NASA centers. The HDU will be composed of contributions of multiple centers into a habitat analog unit to develop a research platform where the integration of the contributions provides a sum benefit that is greater than the parts. Effort will be made to leverage from the current efforts of multi-center technology investments by capitalizing on those research areas and integrating contributions from those participants to form the core of the HDU. This project is part of the strategic investment plan from the ESMD Directorate Integration Office (DIO) strategic vision as part of the surface analog testing which includes the Lunar Electric Rover testing (figure 4).

This HDU will leverage the Johnson Space Center (JSC) Surface Habitat Systems Focused Investment Group (Hab-FIG) work of the Habitat Bench-top Testbed, Hab Systems Management Software, and Hab Command, Communications, and Data Handling (CC\&DH) hardware. The bench-top test-bed will be used as a stepping stone to mature the hardware and software interface prior to installation of updated HDU hardware, software, and technologies. The HDU is an evolutionary approach of build-a-little test-a-little to a higher-fidelity surface analog multi-element integration and testing capability. 


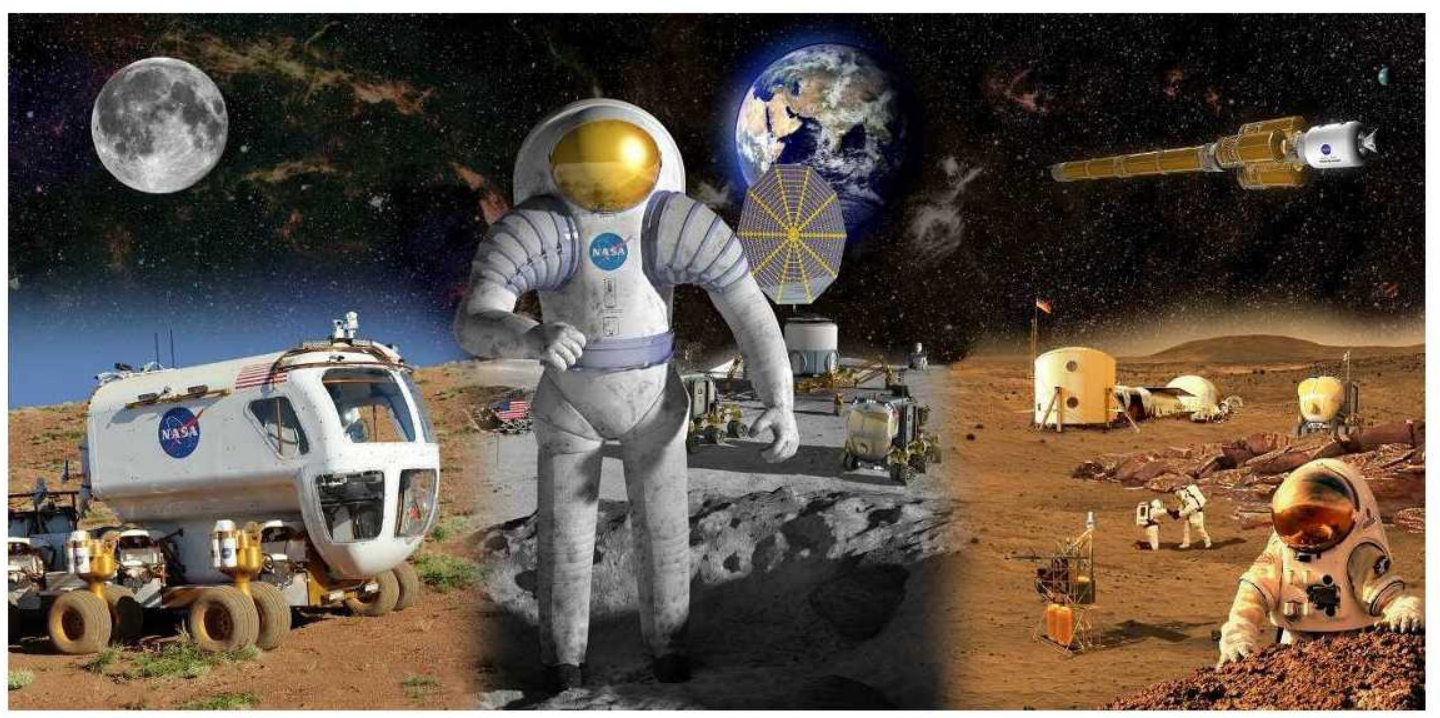

Figure 4, Illustration of Analog Strategic Vision

The HDU Project "Vision" is to develop a fully autonomous habitation system that enables human exploration of space. This will be accomplished by development, integration, testing, and evaluation of habitation systems. The HDU will be utilized as technology pull, testbed, and as an integration capability to advance NASA's understanding of alternative mission architectures, requirements, and operations concepts definition and validation. The HDU Project "Mission" is to develop the Habitat Demonstration Unit - Pressurized Excursion Module (PEM) configuration that will "roll-out" operationally ready for remote testing on July $1^{\text {st }}$ 2010. The HDU Project has numerous goals and objectives defined by the team. They are defined in the bulletized list below.

Goals:

The HDU will be utilized to accomplish the following goals:

- Be a Habitation Technology Pull and Testbed for the ETDP and HRP projects and research.

- Advance the NASA (Smart Buyer/Partner) understanding of surface architectures.

- Advance the NASA understanding of surface architecture requirements definition and validation.

- Advance the NASA understanding of surface architecture operations concepts definition and validation.

- Establish a focused multi-center effort on advanced habitation systems.

- Understand the key driving mission requirements and limitations that result from use of a lunar habitat

- Incorporate agency wide Habitat-related assets. ETDP, Mockups, Mid-X EDU, Micro-Hab, etc.

- Incorporate Sustainability and Green Engineering strategies and approaches into the project 
Objectives:

The HDU will be utilized to accomplish the following objectives:

1. Serve as a platform for integration, tests, and evaluations of developmental hardware and software.

2. Serve as a platform for integration, tests, and evaluations of ETDP technologies.

3. Support $2-4 \mathrm{crew}$ (TBR) for $14-28$ days (TBR) in analog field tests.

4. Define/refine and evaluate "Minimal Habitable Volume" in conjunction with stakeholders.

5. Demonstrate the Logistics-to-living concept and focus on packaging efficiencies as part of an integrated solution set.

6. Demonstrate the 4-port vertical habitat concept.

7. Demonstrate "docking" with the active-active concept on the LER.

8. Support remote site operations for analog testing and evaluations.

9. Align with the LER demonstration unit analog test schedule.

10. Be transportable to remote sites for analog operational testing and evaluations.

The HDU Project top-level milestones are centered on developing two HDU units (HDU1 and HDU2). Each unit will develop various configurations each year based on the needs of the program and architecture being developed. For FY2010 the first generation unit (HDU1) will focus on the PEM configuration. Then in FY2011 the Pressurized Core Module (PCM) configuration will be developed and testing. After which a second generation HDU unit (HDU2) will be manufactured. The HDU2 could be the same shell orientation (vertical can) or a different shell shape. The systems development on the hardware and software integration will be the key to habitation early mitigation and will be applicable to most configurations. The second generation unit will be of higher fidelity with the ability to "seal" the module (To Be Reviewed). The HDU1 will be used in conjunction with the HDU2 in the DRaTS 20012 and 2013 field analogs. Below is a recap of the HDU Project milestones.

\section{Top-Level Milestones}

2010: HDU1 Excursion Module Demo

- 7/2010 HDU1 "Roll-Out", Rock-yard Dry Run

- 8/2010 - 9/2010 Desert RATS Field Analog Test

2011: HDU1 Core Module Demo

- 8/2011 - 9/2011 Desert RATS Field Analog Test

2012: HDU2 Module Demo w/ $1^{\text {st }}$ Gen HDU

- 8/2012 - 9/2012 Desert RATS Field Analog Test

2013: HDU2 Module Demo w/ $1^{\text {st }}$ Gen HDU

- 8/2013 - 9/2013 Desert RATS Field Analog Test 


\section{Technology Collaborations}

The HDU Project is working to "pull" various ETDP project technologies into the HDU1-PEM and HDU1-PCM configurations testing. Technologies being developed from Exploration Life Support, Integrated Systems Health Management, Automation for Operations, Dust Mitigation, Intelligent Software Design, Advanced Environmental Monitoring \& Control, Supportability Technologies, and Advanced Avionics and Computer Processing are being leveraged into the demonstrations. These technologies are also being integrated into the habitat test-be and into the software hab architecture. An interdependency assessment was performed to determine which ETDP projects would have potential collaborations and products to integrate into the HDU project (fig 5).

\begin{tabular}{|c|}
\hline $\begin{array}{l}\text { Exploration Technologies Development Program } \\
\text { ETDP Project }\end{array}$ \\
\hline Structures, Materials, \& Mechanisms \\
\hline Propulsion \& Cryogenic Advanced Development \\
\hline Cryogenic Fluid Management system \\
\hline Energy Storage \& Power Systems \\
\hline $\begin{array}{l}\text { Advanced Avionics and Computer Processing } \\
\text { (High Performance \& Radiation Hardened Electronics) }\end{array}$ \\
\hline Fission Surface Power Systems \\
\hline In-Situ Resource Utilization \\
\hline Supportability \\
\hline Human Robotics Systems \\
\hline Thermal Protection systems \\
\hline Advanced Composites Technologies \\
\hline Dust Mitigation \\
\hline Thermal Control for Surface Systems \\
\hline Integrated Systems Health Management \\
\hline Autonomy for Operations \\
\hline Intelligent Software Design \\
\hline Autonomous Landing \& Hazard Avoidance Technology \\
\hline Automated Rendezvous \& Docking Sensors \\
\hline Exploration Life Support \\
\hline Advanced Environmental Monitoring \& Control \\
\hline Fire Prevention, Detection, \& Suppression \\
\hline Extra Vehicular Activity (EVA) Technology \\
\hline ISS Research \\
\hline Radiation Protection Technologies \\
\hline Surface Communications \\
\hline Advanced Habitation Systems \\
\hline Scavenging, Recycling \& Manufacturing \\
\hline
\end{tabular}

Possible Collaboration HDU1-PEM

Figure 5, ETDP Project Collaborations with HDU Project 


\section{Risk Mitigation}

The HDU Project implemented a risk-based approach to manage the project development. The team determined the areas of risks and developed strategies to mitigate their impact to the project's success. In concert with the establishment of the interface definitions, the HDU team will utilize scheduled pre-integration activities, integration tools, and the habitat test-bed to buy-down risk prior to integration of systems within the HDU shell.

As part of the HDU Project objective, the team reviewed the 2008 Surface Habitation Risk Workshop results. These risks will be used to guide prioritization of test objectives and assist the LSSPO Habitation Team in buying down some of these risks. The following table is an excerpt from the 2008 Surface Habitation Risk Workshop:

Table 1, Surface Habitation Risks (partial list)

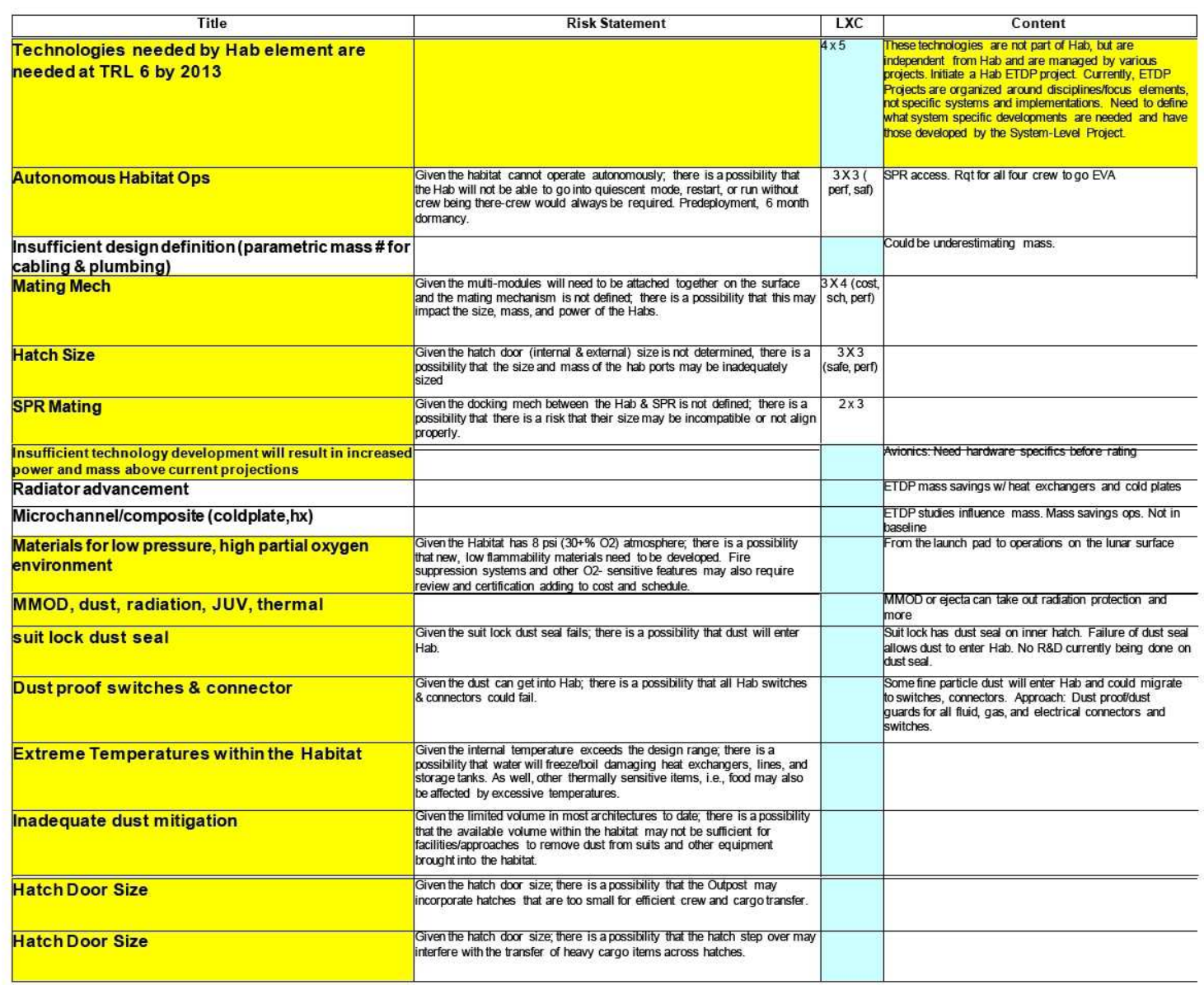




\section{HDU Project Integration}

\section{Configuration Integration}

The HDU team will utilize Computer-Aided Design (CAD) and Simulations early in the development flow across all efforts to test form, fit, integration, assembly, and basic functions as subsystem designs mature. It is expected that these simulation opportunities will be present throughout the lifecycle. Periodic synchronization events occur during development and extending through the testing. The events will include updates to models and simulations (from CAD End Item Developers and the Langley models) to reflect current operations concepts and current system and subsystem designs.

\section{Systems Integration}

The HDU team will utilize fit-check opportunities in the development flow at JSC to allow hardware to be temporarily installed for form and fit. These opportunities will occur from days to months prior to the hardware delivery date depending on complexity and availability. An integrated schematic has been developed that layers the subsystems and functional capabilities of the HDU1-PEM configuration. For a more detailed description please see reference \#3, Habitat Demonstration Unit (HDU) Project Systems Integration.

\section{Test Operations Integration}

The HDU team will utilize the Habitat Test-Bed (HaT) in JSC Building 220 as a bench-top platform for early avionics, communications, and power systems hardware and software integration prior to final installation of components within the HDU1PEM. These opportunities will occur from approximately two weeks to three months

prior to the hardware delivery date depending on complexity and availability. For a more detailed description please see reference \#4, Habitat Demonstration Unit (HDU) Project Testing Operations.

\section{Technology Integration}

The HDU Team will utilize and leverage the Exploration Technology and Development Program (ETDP) projects expertise, technologies, and products to focus integrated testing and demonstrations pertaining to surface habitation objectives. The HDU team mapped the ETDP technologies opportunities to the HDU1-PEM configuration. Figure 6 shows in RED the interdependency mapping of the ETDP and Human Research Program (HRP) products and research that can be leveraged into the HDU1-PRM test objectives. 


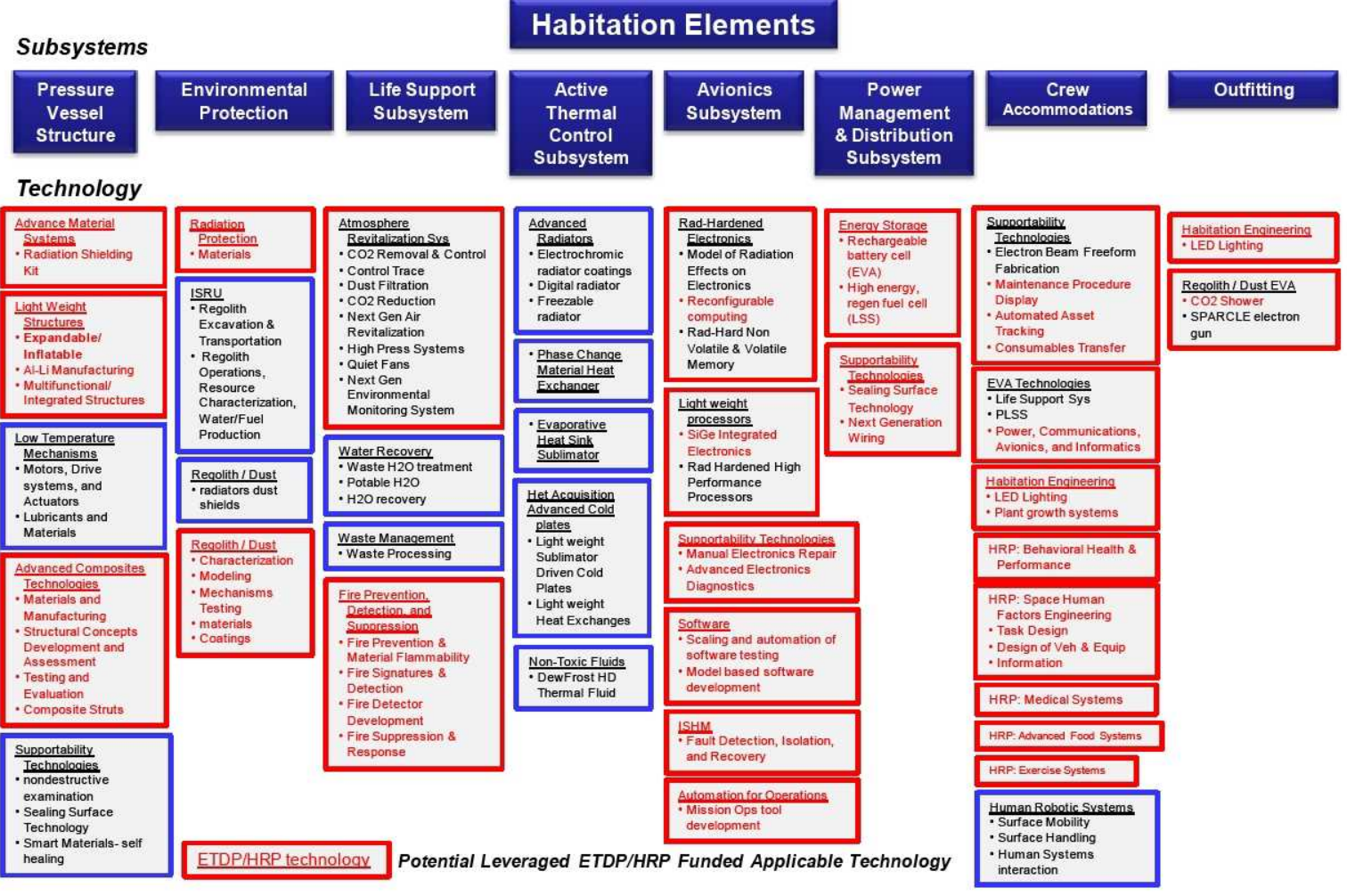

Figure 6, ETDP \& HRP Mapping to the HDU Project

Below is a list of ETDP projects with the greatest opportunity for integration, collaborations, and leveraging of technologies for FY10 PEM configuration. Table 2 shows in GREEN the technology products being "pulled" and integrated into the HDU1-PEM FY10 test objectives.

- Exploration Life Support

- Integrated Systems Health Management

- Automation for Operations

- Advanced Avionics and Computer Processing

- Intelligent Software Design

- Dust Mitigation

- Advanced Environmental Monitoring \& Control

- Supportability Technologies 
Table 2, ETDP Technologies "Pull" into the HDU Project

\begin{tabular}{|c|c|}
\hline \multicolumn{2}{|c|}{ ETDP Opportunities } \\
\hline Advanced Material Systems & Automation for Operations \\
\hline Radiation Shielding Kit & Mission Ops tool development \\
\hline Light Weight Structures & Software \\
\hline Expandable/ Inflatable & Scaling and automation of software testing \\
\hline Al-Li Manufacturing & Model based software development \\
\hline Multifunctional/ Integrated Structures & SHM \\
\hline Advanced Composites Technologies & Fault Detection, Isolation, and Recovery \\
\hline Materials and Manufacturing & Light weight processors \\
\hline Structural Concepts & SiGe Integrated Electronics \\
\hline Development and Assessment & Rad-Hardened Electronics \\
\hline Testing and Evaluation & Model of Radiation Effects on Electronics \\
\hline Composite Struts & Reconfigurable computing \\
\hline Radiation Protection & Rad-Hard Non Volatile \& Volatile Memory \\
\hline Materials & Supportability Technologies \\
\hline Regolith / Dust & Electron Beam Freeform Fabrication \\
\hline Characterization & Maintenance Procedure Display \\
\hline Modeling & Automated Asset Tracking \\
\hline Mechanisms Testing & Consumables Transfer \\
\hline materials & Advanced Electronics Diagnostics \\
\hline $\mathrm{CO} 2$ Shower & Manual Electronics Repair \\
\hline SPARCLE electron gun & nondestructive examination \\
\hline Lotus Coating & Sealing Surface Technology \\
\hline Coatings & Smart Materials- self healing \\
\hline Atmosphere Revitalization Sys & Sealing Surface Technology \\
\hline CO2 Removal \& Control & Next Generation Wiring \\
\hline Control Trace & Fire Prevention, Detection, and Suppression \\
\hline Dust Filtration & Fire Prevention \& Material Flammability \\
\hline CO2 Reduction & Fire Signatures \& Detection \\
\hline Next Gen Air Revitalization & Fire Detector Development \\
\hline High Press Systems & Fire Suppression \& Response \\
\hline Quiet Fans & Het Acquisition \\
\hline Next Gen Environmental Monitoring System & Advanced Cold plates \\
\hline Water Recovery & Light weight Sublimator Driven Cold Plates \\
\hline Waste $\mathrm{H} 2 \mathrm{O}$ treatment & Light weight Heat Exchanges \\
\hline Potable $\mathrm{H} 2 \mathrm{O}$ & EVA Technologies \\
\hline $\mathrm{H} 2 \mathrm{O}$ recovery & Life Support Sys \\
\hline Waste Management & PLSS \\
\hline Waste Processing & Power, Communications, Avionics, and Informatics \\
\hline Trash Compaction & Energy Storage \\
\hline Advanced Environmental Monitoring \& Control & Rechargeable battery cell (EVA) \\
\hline ENOSE & High energy, regen fuel cell (LSS) \\
\hline VCAM & \\
\hline Habitation Engineering & \\
\hline LED Lighting & \\
\hline \begin{tabular}{|l} 
Plant growth systems \\
Dust Vacuum
\end{tabular} & \\
\hline
\end{tabular}

\section{Project Organization}

The HDU team implements a distributed and matrixed team approach to manage the project's objectives, resources and execution. The HDU Management team organization is shown in figure 7. The second tier integration strategy in depicted in figure 8. The HDU management team is comprised of three main integration functions of Design Integration, Scott Howe/JPL; Systems Integration, Tracy Gill/KSC; and Test Operation Integration, Terry Tri/JSC. Each HDU1 subsystem functional area has an "Integration Lead" that coordinates between the ETDP Technology Lead and the LSS Architecture Lead to ensure both the latest 
technologies and architecture definitions are being incorporated into the configurations and test objectives.

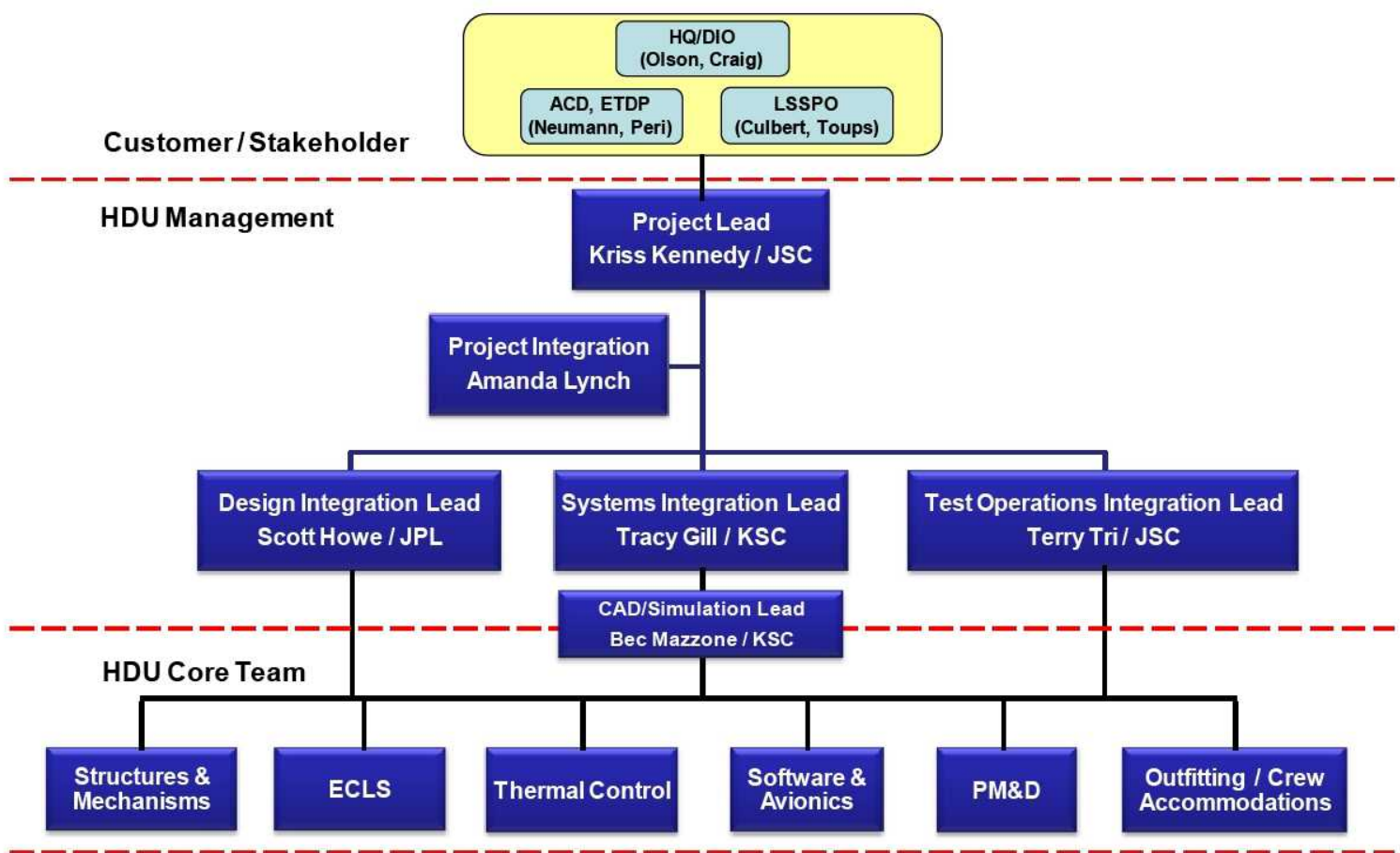

HDU Extended Team

Figure 7, HDU Project Organization

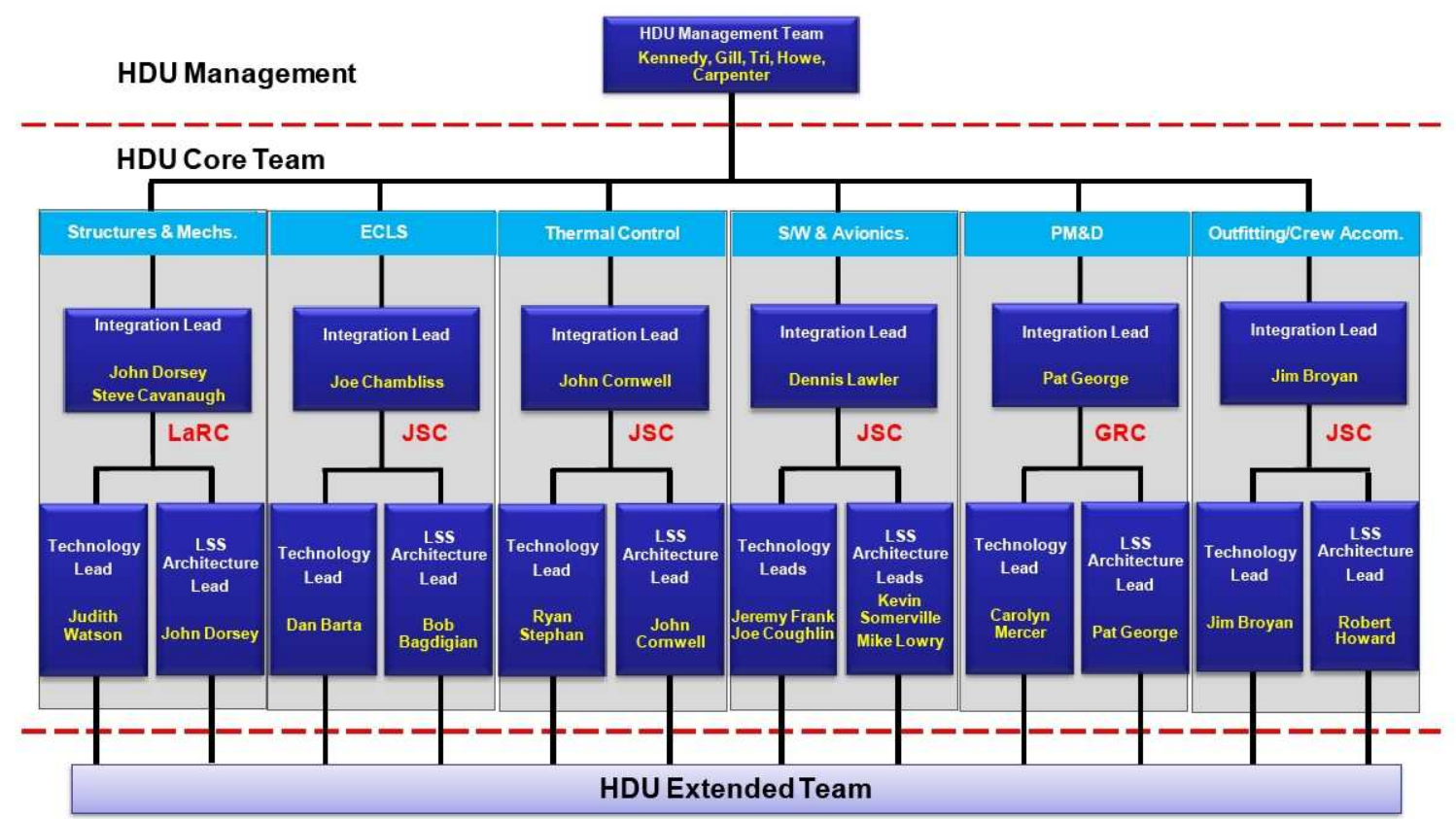

Figure 8, HDU Project Team Integration 


\section{Project Milestones}

The HDU Project milestones are aligned with delivery of habitation configurations and prototypes for testing yearly in September. Accordingly the project manages its objectives, resources, assembly, and check-out prior to the August pre-test dry-runs. Figure 9 shows the multi-year HDU development and integration schedule. As previously described, there will be two (2) HDUs built (HDU1 and HDU2) over the next several years.

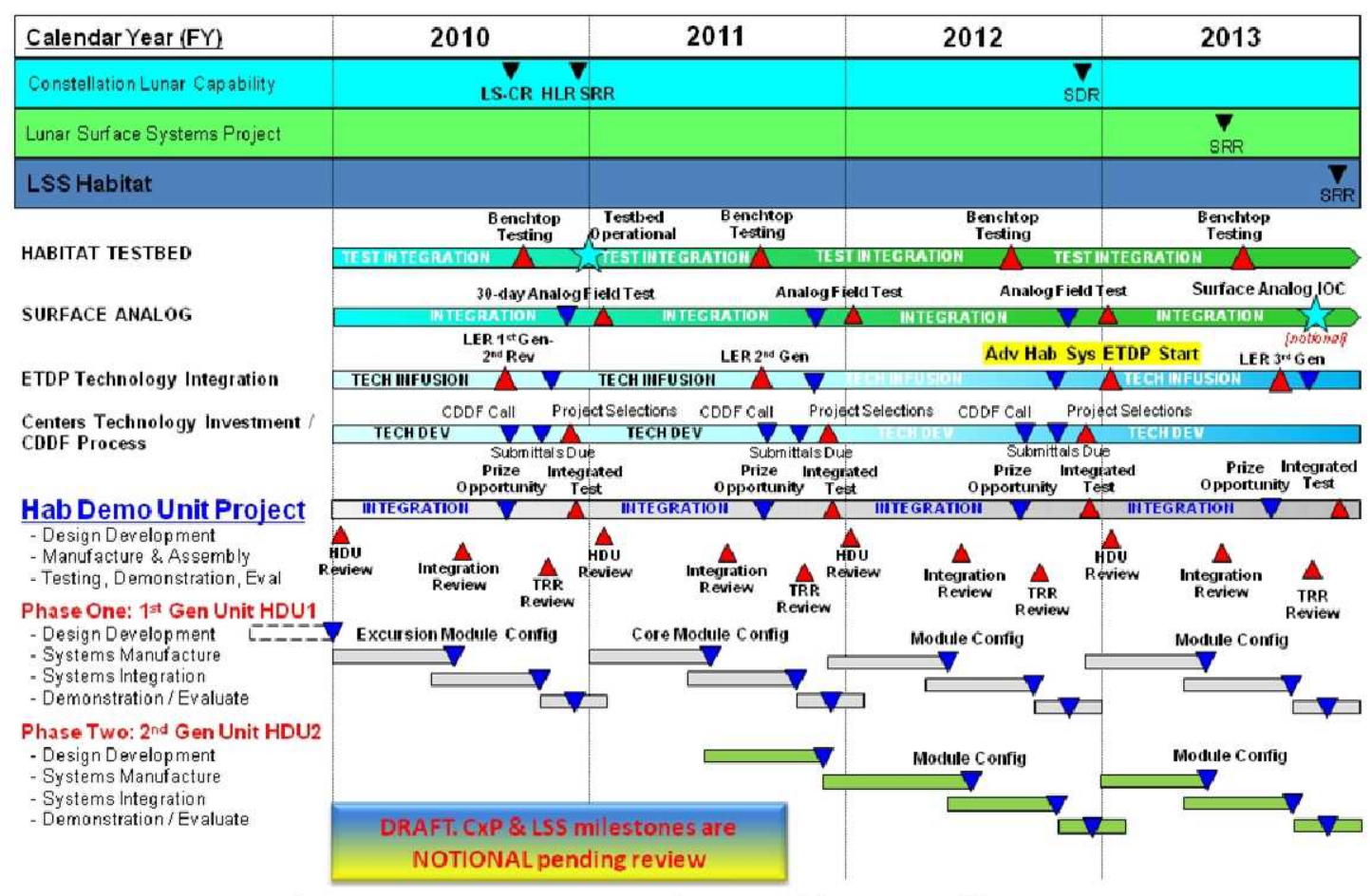

Figure 9, FY10 HDU Project Multi-Year Milestones

The FY10 HDU Project milestone reviews are aligned with delivery of the first generation HDU1-PEM configuration. The reviews are set up to provide a check-point on development progress while proceeding to the next phase of development. Below and figure 10 are the high level project milestones.

- 9/23/09 - HDU1-PEM Configuration \& System Implementation Review

- 10/7/09 - Shell CDR

- 10/14/09 - CAD Integration Review

- 11/18/09 - Preliminary Integration Review (PIR)

- Jan 2010 - Final Integration Review (FIR)

- February - March 2010 - Testbed Integration

- May/June 2010 - HDU1-PEM Integrated Systems Checkout

- July 2010 - HDU1-PEM Roll-Out B220

- July 2010 - HDU1-PEM Rock-Yard Dry Run Testing

- Aug-Sept 2010 - HDU1-PEM Field Analog Testing 


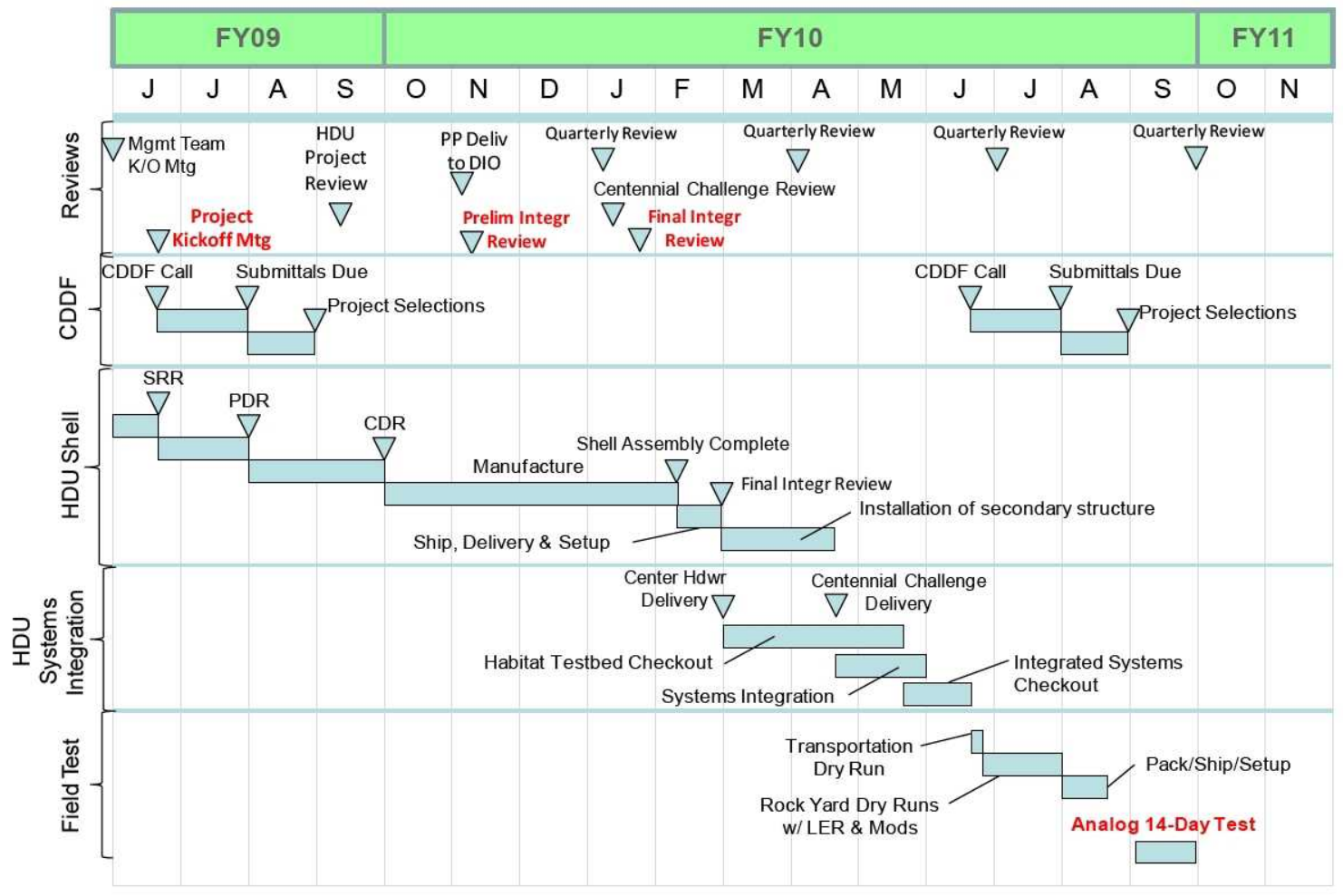

Figure 10, FY10 HDU Project Milestones

\section{HDU1 Pressurized Excursion Module Configuration}

The HDU1-PEM configuration is based on the lunar architecture scenario 12.1; reference \#2, Constellation Architecture Team: Lunar Outpost Scenario 12.1 Habitation Concept. As previously described (figure 2), the PEM configuration is of the "excursion" module layout that functionally support crew IVA Geology science, medical operations, IVA suit maintenance and Airlock operations, general maintenance, and logistics stowage. Based on the PEM configuration the HDU team designated a pie-shaped approach of sectional integration and manufacturing, figure 11.

The HDU strategy is to designate the earliest sections as those in the vicinity of the General Maintenance workstation, Section F, and by the placement of the core systems of the HDU in that area. The General Maintenance workstation is one of four quadrants of the PEM layout with the other three being an Extravehicular Suit Maintenance area, a Medical Operations workstation, and a Geology Laboratory area. Core systems include the power input and distribution, the computer system, and the heat pump which will be used for environmental conditioning. A HDU1-PEM CAD representation from the systems modeling tool is illustrated in figures 12 and 13 . 


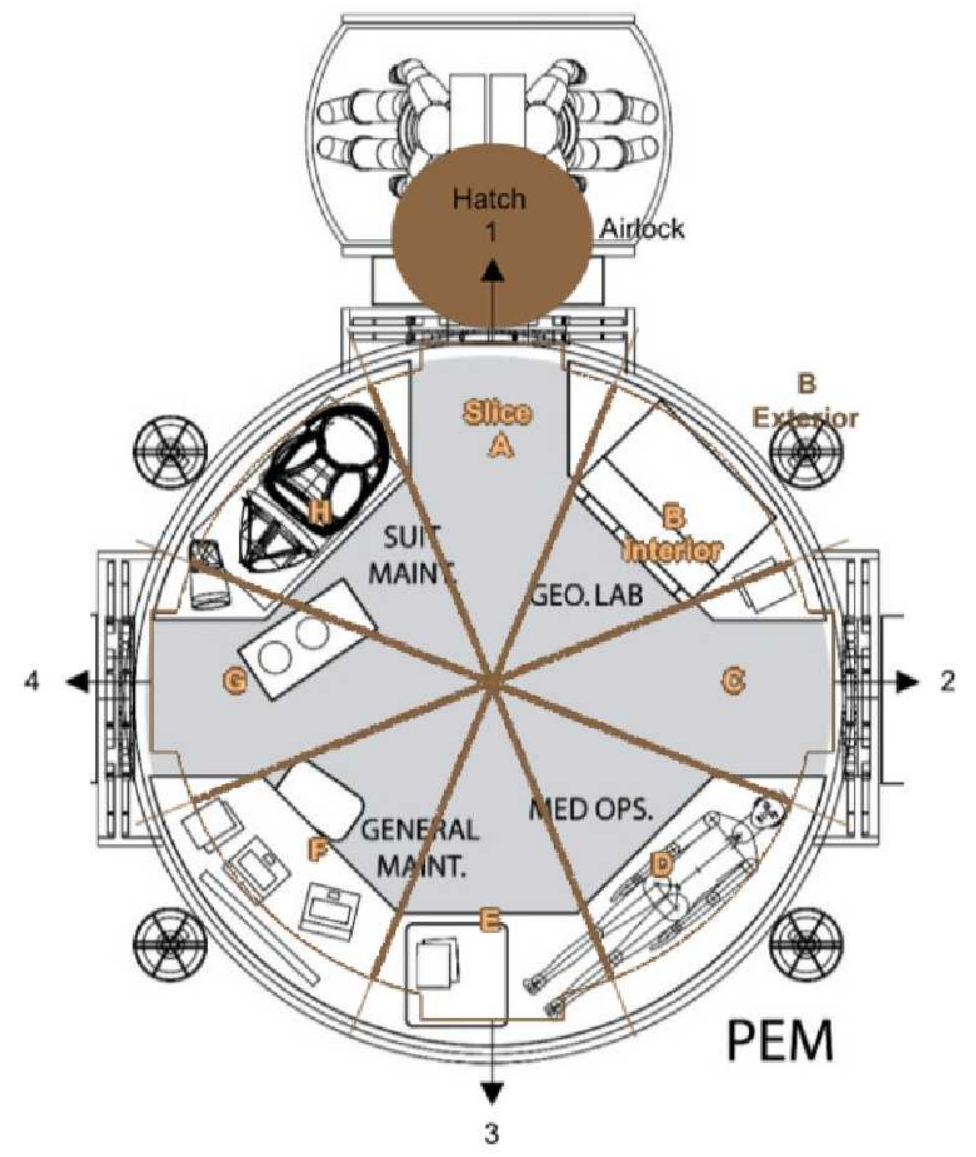

Figure 11, HDU1-PEM Integration Sections

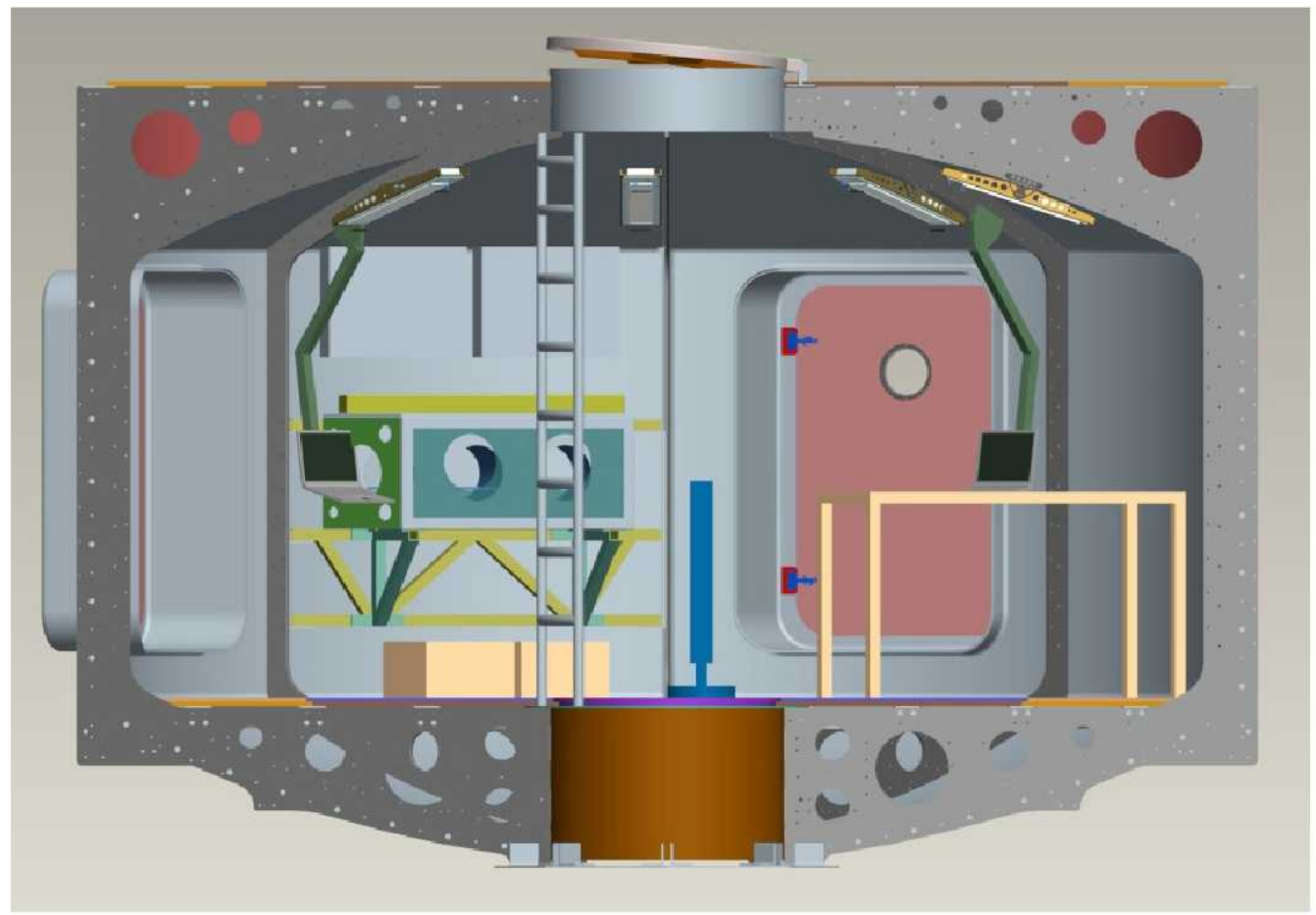

Figure 12, CAD Integration Cross-Section View of HDU1-PEM 


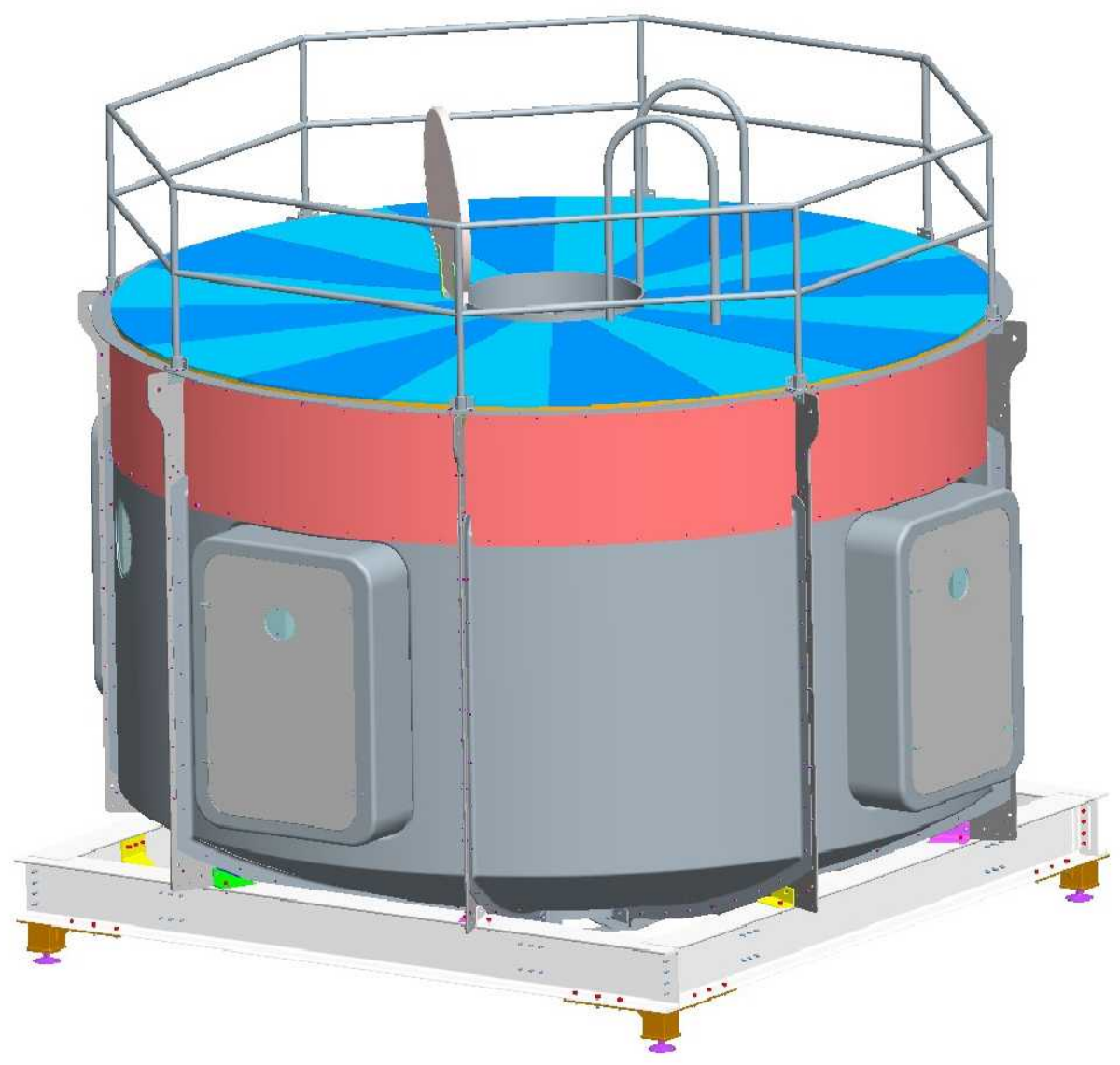

Figure 13, Assembled HDU1-PEM Mounted on Cradle for Desert RaTS 2010

\section{Centennial Challenge Incorporation}

The HDU Project has proposed three Centennial Challenge opportunities and is awaiting the outcome of the NASA Headquarters selection process to see if they will go forward for competition. These challenges are to build and demonstrate innovations and technologies focused on lunar surface habitation. The three challenges are for an inflatable upper level "loft" for the habitat, an inflatable airlock for extravehicular activity, and logistics-to-living concept which takes elements of packaging and utilizes them for living accommodations such as curtains, dividers, work surfaces, insulation, etc. Notional concepts and proposals may be different innovative shapes or sizes. The HDU has been designed to accommodate these challenge opportunities and the winners will have their contribution integrated with the HDU during the Desert RaTS 2010 campaign.

\section{Summary}

The Habitat Demonstration Unit project is constructing a habitat shell that will be used to integrate and mitigate early development risks and technologies. The 
HDU will assist the exploration architecture team in defining and validating various architectures, concepts of operations, and habitation requirements. For 2010, the configuration represented by the HDU1 will be the Pressurized Excursion Module of the lunar architecture. This configuration will be tested in the 2010 NASA Desert Research and Technology Studies campaign. There have been significant challenges to accelerate manufacturing and integration are being addressed within several aspects of the HDU project strategy. The HDU project is using computer aided design for the layout and integration of systems and the use of fit-check opportunities with the unit to catch integration challenges early. The utilization of a Habitat Testbed avionics platform will mitigate the risk of integrating the systems together for the first time within the HDU1-PEM. Finally, the entire concept of operations from the planning of the manufacturing, shipment, and integration to the field operations have all been factored into the design of the HDU1-PEM to streamline the integration activities that will enable the project to meet the ambitious timeline for deployment in July 2010.

\section{References}

1. AS Howe; T Hong; B Hunkins; DS Hafermalz; K Kennedy; L Toups (2010). Mobile Field Analog for Lunar Habitat Integrated System Health Monitoring. Proceedings of the Twelfth Biennial ASCE Aerospace Division International Conference on Engineering, Science, Construction, and Operations in Challenging Environments (Earth \& Space 2008); Honolulu, Hawaii, 14-17 March 2010. Reston, Virginia, USA: American Society of Civil Engineers.

2. AS Howe; G Spexarth; L Toups; R Howard; M Rudisill; J Dorsey; et al (2010). Constellation Architecture Team: Lunar Outpost Scenario 12.1 Habitation Concept. Proceedings of the Twelfth Biennial ASCE Aerospace Division International Conference on Engineering, Science, Construction, and Operations in Challenging Environments (Earth \& Space 2008); Honolulu, Hawaii, 14-17 March 2010. Reston, Virginia, USA: American Society of Civil Engineers.

3. TR Gill; KJ Kennedy; TO Tri; AS Howe (2010). Habitat Demonstration Unit (HDU) Project Systems Integration. Proceedings of the Twelfth Biennial ASCE Aerospace Division International Conference on Engineering, Science, Construction, and Operations in Challenging Environments (Earth \& Space 2008); Honolulu, Hawaii, 14-17 March 2010. Reston, Virginia, USA: American Society of Civil Engineers.

4. TO Tri; KJ Kennedy; TR Gill; AS Howe (2010). Habitat Demonstration Unit (HDU) Project Testing Operations. Proceedings of the Twelfth Biennial ASCE Aerospace Division International Conference on Engineering, Science, Construction, and Operations in Challenging Environments (Earth \& Space 2008); Honolulu, Hawaii, 14-17 March 2010. Reston, Virginia, USA: American Society of Civil Engineers. 